\title{
Rapid evolution of HIV-1 to functional CD8+ T-cell rResponses in humanized BLT mice
}

\author{
TE Dudek ${ }^{*}$, DC No ${ }^{1}$, E Seung ${ }^{2}$, V Vrbanac ${ }^{2}$, L Fadda ${ }^{1}$, KF Bryant $^{3}$, M Altfeld $^{1}$, AD Luster ${ }^{2}$, DM Knipe $^{3}$, AM Tager $^{2}$, \\ TM Allen ${ }^{1}$
}

From AIDS Vaccine 2012

Boston, MA, USA. 9-12 September 2012

\section{Background}

The newly developed humanized BLT (bone marrow, liver, thymus) mouse model holds great promise to facilitate the in vivo study of human immune responses. However, little data exists regarding the extent to which cellular immune responses in humanized BLT mice accurately reflect those seen in humans.

\section{Methods}

Multiple sets of humanized BLT mice reconstituted with distinct human tissues were infected with the HIV-1 molecular clone JR-CSF. Mice were then bled every two weeks to measure plasma viral loads, sequence evolution and cellular immune responses.

\section{Results}

During the acute phase of infection BLT mice rapidly mounted multiple HIV-1-specific CD8+ cellular immune responses against normally immunodominant human CD8 epitopes, with rapid and reproducible viral escape observed within epitopes that similarly tend to escape early in humans. CD8+ T cell responses and viral escape to these same epitopes was confirmed in mice reconstituted with distinct human tissue but expressing the same restricting HLA alleles. Importantly, in two independent groups of mice expressing HLA-B*57 we observed the rapid induction of $\mathrm{CD} 8+\mathrm{T}$-cell responses against a number of $B * 57$-restricted responses at frequencies similar to those seen in humans, including the normally immunodominant B*57-IW9, -KF11 and -TW10 epitopes in Gag from which the virus failed to rapidly escape. As in humans, the presence of these conserved responses correlated with significantly greater control over early viral

${ }^{1}$ Ragon Institute of MGH, MIT and Harvard, Charlestown, MA, USA Full list of author information is available at the end of the article replication. Preliminary vaccine studies in BLT mice support the ability of conventional approaches to induce $\mathrm{CD} 8+\mathrm{T}$ cell responses and suppress viral loads.

\section{Conclusion}

These studies indicate that the specificity, magnitude, and immunodominance patterns of human CD8+ T-cell responses in humanized BLT mice appear to closely reflect those of humans. These data support the potential of humanized BLT mice to significantly advance HIV-1 vaccine development, providing a critical new tool to complement the SIV infected macaque model.

\section{Author details \\ ${ }^{1}$ Ragon Institute of MGH, MIT and Harvard, Charlestown, MA, USA. ${ }^{2}$ Center for Immunology and Inflammatory Diseases, MGH, Boston, MA, USA. ${ }^{3}$ Harvard Medical School, Boston, MA, USA.}

Published: 13 September 2012

doi:10.1186/1742-4690-9-S2-P249

Cite this article as: Dudek et al.: Rapid evolution of HIV-1 to functional CD8+ T-cell rResponses in humanized BLT mice. Retrovirology 2012 9(Suppl 2):P249.

Submit your next manuscript to BioMed Central and take full advantage of:

- Convenient online submission

- Thorough peer review

- No space constraints or color figure charges

- Immediate publication on acceptance

- Inclusion in PubMed, CAS, Scopus and Google Scholar

- Research which is freely available for redistribution

Submit your manuscript at www.biomedcentral.com/submit C Biomed Central 